\title{
Defendamos nuestra ciudad
}

Colegio de Arquitectos de Chile

\section{Filiación}

Comisiones del Colegio de Arquitectos de Chile, Asociación Gremial:

Comisión de Desarrollo Urbano, Comisión de Medio Ambiente, Comisión de Leyes y Ordenanzas, Comisión de Concursos, Comisión de Arquitectura del Paisaje, Comisión de Tecnología, Comisión de Arquitectura Educacional, Comisión de Gestión Profesional, Comisión de Derechos Humanos, Comisión de Gestión Inmobiliaria, Comisión de Aranceles, Comisión del Patrimonio, Comisión de Arquitectos Tasadores.

\section{Resumen}

Las Comisiones del Colegio de Arquitectos de Chile que suscriben este documento, se dirigen a las autoridades y a los habitantes del Gran Santiago protestando por las modificaciones que se pretende realizar al Plan Regulador Metropolitano de Santiago sin participación adecuada de la comunidad. Las Comisiones rechazan las modificaciones a las áreas de interés silvo-agropecuario y a las áreas verdes del área metropolitana, e invitan a la comunidad a sumarse a la protesta ciudadana ante estas medidas, gravemente perjudiciales para la ciudad, el nivel de vida de sus habitantes y el medio ambiente. Declaración entregada en conferencia de prensa realizada en la sede del Colegio de Arquitectos de Chile, en Santiago, 9 de junio de 2001.

\section{Palabras clave}

Modificación al Plan Metropolitano de Santiago de Chile (2001).

\section{Abstract}

The Committees of the Chilean College of Architects reject modifications of agricultural and forestal zones and of metropolitan green areas, and invite the community to join the citizens' protest.

\section{Key words}

Metropolitan Plan Amendment of Santiago de Chile (2001).

\section{Sumario}

Introducción

1.- Rechazar las modificaciones al sistema metropolitano de áreas verdes y recreación

2.-Rechazar las modificaciones a los conjuntos habitacionales financiados con subsidios del Estado

3.-Rechazar las modificaciones de las áreas de interés silvo-agropecuario. 


\section{Introducción}

La planificación urbana es un instrumento que nos ayuda a hacer posible, dentro del contexto general del país, la ciudad que necesitamos y queremos; su carencia impide el desarrollo equilibrado y sustentable de los complejos urbanos. La planificación territorial es un medio imprescindible para aprovechar las ventajas de los procesos de desarrollo y, nos permite también, prever las circunstancias adversas o no deseables.

Nos preocupan profundamente la serie de acciones anunciadas y emprendidas por las autoridades ligadas al sector del desarrollo urbano, que no están tomando en cuenta los instrumentos de planificación existentes o están simplemente permitiendo que se rebase su normativa. Afirmamos responsablemente que en este contexto de riesgos, se ubican las modificaciones propuestas por la Secretaría Regional Ministerial de Vivienda y Urbanismo al Plan Regulador Metropolitano de Santiago (PRMS).

Estas modificaciones se refieren a las siguientes materias: primero, a la intervención en el Sistema Metropolitano de Áreas Verdes y Recreación; segundo, a introducir modificaciones a los conjuntos de viviendas financiadas con subsidio del Estado y, en tercer lugar, la construcción de loteos en las Áreas de Interés Silvo-agropecuario, zonas rurales que rodean la gran ciudad.

En la actualidad, nuestras ciudades tienen que funcionar con una Ley General de Urbanismo y Construcciones obsoleta, con una Ordenanza General Ilena de parches y contradicciones que norma una ley inapropiada al desarrollo actual y sin una política nacional explícita para el sector del desarrollo urbano.

A todo esto se agrega ahora este proceso de cambios tan importantes al PRMS, que termina por definir un clima de incertidumbre, tanto para los habitantes como para los inversores inmobiliarios, lo que atenta contra el tan ansiado desarrollo de la actividad de la construcción.

Ante las tres modificaciones que se pretende introducir en el Plan Regulador Metropolitano de Santiago, sin la debida participación de la comunidad, convocamos a los habitantes del Gran Santiago para:

\section{Primero: rechazar las modificaciones al sistema metropolitano de áreas verdes y recreación, por las siguientes razones:}

- Por constituir un conjunto de disposiciones confusas y poco transparentes, con textos tan complicados que, además de hacer difícil su comprensión, se prestan a las más diversas interpretaciones.

- Por permitir la construcción de edificios en sectores ya destinados a áreas verdes con el justificativo de no encontrarse en la actualidad "consolidadas", lo que constituye 
un despojo a los ciudadanos del sector, ya que son superficies que no se podrán recuperar.

- Las modificaciones se aplicarán a todas las comunas del Área Metropolitana, sin hacer distinciones entre unas y otras y sin que nada asegure la no disminución de las superficies de las áreas verdes en una comuna en particular. Esta circunstancia se encamina a acentuar las desigualdades sociales entre los diferentes sectores de la ciudad.

- La modificación, al permitir edificios en las áreas verdes y áreas verdes donde deben haber construcciones, tiende a desarmar el sistema de áreas verdes y recreación establecidas en el Plan Regulador Metropolitano de Santiago, resultado de un consensual proceso de planificación.

- La misma autoridad que decidirá cuáles áreas verdes serán desafectadas negociará con los inversionistas, lo que otorga poca transparencia al procedimiento.

- La ubicación del área verde que se restituye en otro lugar de la ciudad, de acuerdo a lo propuesto, será decisión del inversionista condicionada por el mercado y sin un proceso de planificación concebido previamente.

- La ley establece que los usos del suelo y las condiciones de edificación deben estar normados y definidos por los instrumentos de planificación que la misma ley define, y de ningún modo contempla la posibilidad que estas prerrogativas estén radicadas en una autoridad administrativa; en consecuencia, la iniciativa es ilegal.

\section{Segundo: rechazar las modificaciones a los conjuntos habitacionales financiados con subsidios del Estado}

- Estos conjuntos se podrán construir en áreas urbanas consolidadas o en Zonas Urbanizables con Desarrollo Condicionado de la provincia de Chacabuco, con un mínimo de 300 viviendas y rebasando la densidad establecida por el plan regulador respectivo, hasta llegar a 500 habitantes por hectárea.

Para ese tamaño y densidad - según las disposiciones vigentes - le corresponde solamente $1,6 \mathrm{~m} 2$ por habitante de áreas verdes, superficie muy insuficiente si se la compara con los $12 \mathrm{~m} 2$ que recomienda la Organización Mundial de la Salud.

En cuanto a superficie para equipamiento, las actuales disposiciones obligan a los inversionistas a ceder algo más de $800 \mathrm{~m} 2$, en que no cabe ni una escuela, quedando todos los otros equipamientos sin lugar para asentarse. Así, estos futuros habitantes carecerán de servicios de salud, seguridad, recintos para las juntas de vecinos y demás organizaciones comunitarias, superficies para juegos infantiles, deportes y esparcimiento, lo que constituye una inhumanidad y hacen perversa esta iniciativa. 
http://revistaurbanismo.uchile.cl

- Se deja a la iniciativa del mercado la definición de los lugares en que se levantarán estos conjuntos de alta densidad, lo que es muy peligroso para las comunas pobres, ya que estas iniciativas pueden deteriorar aún más los sectores que ya hoy día son bolsones de pobreza carentes de equipamiento. Solamente las disposiciones de los planes reguladores defienden a las comunas de estas anomalías.

\section{Tercero: rechazar las modificaciones de las áreas de interés silvoagropecuario, porque:}

- La construcción de enormes núcleos habitacionales, en las zonas rurales próximas a la gran ciudad, es una iniciativa errónea, ya que estas áreas constituyen las últimas e irrecuperables defensas del medio ambiente y su invasión creará problemas ecológicos irreversibles.

- Se vulnera claramente el artículo 55 de la Ley General de Urbanismo y Construcciones que prohibe los loteos y urbanizaciones fuera del límite urbano y que no permite construcciones que no estén destinadas a la explotación agrícola; en consecuencia, la modificación es ilegal.

- La extensión de manera irresponsable de la ciudad sobre los campos aledaños crecimiento tipo "mancha de aceite"- es el mal principal que ha sufrido Santiago en los últimos cincuenta años, obligando a la extensión desmesurada de las redes de infraestructura y a la ubicación de poblaciones sin servicios y equipamientos suficientes. Nada hay en el texto de la modificación que asegure que esto no será así.

\section{$\bullet$}

De hecho, mediante esta modificación el Estado está renunciando a su rol de planificar la ciudad, ya que la localización de los loteos está dependiendo del mercado.

- Se aumenta la duración de los viajes que los habitantes deben realizar para sus actividades habituales, que además de incrementar los contaminantes del aire, restan tiempo al descanso, esparcimiento y a la vida familiar.

- De acuerdo a nuestra información, existen alrededor de 36 mil hectáreas disponibles dentro del radio urbano (26 mil en la provincia de Chacabuco y 10 mil en el resto de Santiago); si el crecimiento de la ciudad es de mil hectáreas al año, se tendrían asegurados los próximos 36 años para asentar cerca de 3 millones de habitantes, sin que la superficie urbana se incremente.

- Por último, la creación de esta nueva oferta de posibles áreas urbanas en el entorno rural de Santiago, además de no significar un proceso inmediato de construcción, desatará inevitablemente una especulación inmobiliaria con la venta y reventa de terrenos en verde, repitiendo el mismo vergonzoso proceso que experimentó la ciudad en el año 1979. 
http://revistaurbanismo.uchile.cl

Sostenemos que las modificaciones que se pretende realizar son gravemente perjudiciales para la ciudad, para el nivel de vida de sus habitantes y para el medio ambiente; en consecuencia, junto con solicitar a las autoridades pertinentes retirar estas modificaciones, convocamos a nuestros colegas arquitectos y a la ciudadanía en general a manifestar nuestro más enérgico rechazo.

\author{
Comisión de Desarrollo Urbano \\ Comisión de Medio Ambiente \\ Comisión de Leyes y Ordenanzas \\ Comisión de Concursos \\ Comisión de Arquitectura del Paisaje \\ Comisión de Tecnología \\ Comisión de Arquitectura Educacional \\ Comisión de Gestión Profesional \\ Comisión de Derechos Humanos \\ Comisión de Gestión Inmobiliaria \\ Comisión de Aranceles \\ Comisión del Patrimonio \\ Comisión de Arquitectos Tasadores
}

Colegio de Arquitectos de Chile A.G. 